\title{
Kutsadurari aurre egiteko muskuiluen erantzun biologikoak eta euren aldakortasun naturala
}

\author{
(Biological responses of mussels to pollution and their natural variability)
}

\author{
Esther Blanco-Rayón ${ }^{1,2}$, Ionan Marigómez ${ }^{1,2^{*}}$, Urtzi Izagirre ${ }^{1,2}$
}

${ }^{1}$ CBET Res. Grp., Dept. Zoology \& Animal Cell Biology, Univ. Basque Country (UPV/EHU), Leioa,

Basque Country, Spain

${ }^{2}$ Research Centre for Experimental Marine Biology and Biotechnology (Plentzia Marine Station; PiEUPV/EHU), Univ. Basque Country, Plentzia, Basque Country, Spain

LABURPENA: Itsas baliabideen kontserbazio eta kudeatze sostengarrirako ezinbesteko beharrizan gisa antzeman da itsas kutsadura ebaluatzea. Muskuilu begiraleek poluitzailei aurka egiteko erakusten dituzten biomarkatzaile izeneko erantzun biologikoak oinarri duten monitorizazio-programak itsas ekosistemen osasuna ebaluatzeko tresnatzat aitortu dira. Kutsatzaile eta faktore naturalen arteko zein faktore naturalen euren arteko elkarreraginak direla-eta poluitzailei aurkako erantzun biologikoak interpretatzea zaila izan daiteke. Biomarkatzaileen aldakortasun naturalaren nondik nora doan eta poluzioaren efektu biologikoaren ebaluaketan aldakortasun horrek biomarkatzaileen interpretazio zuzena nola eragin dezaken zehazteak garrantzi itzela du. Lehen aurrerapausoak eginda dauden arren, biomarkatzaileen aldakortasun naturala guztiz ulertzeko ikerketek urrutiago jo beharra dute. Horrela ebaluaketa-jarraibideak garatu ahal izango ditugu. Jarraibide horiek, itsas poluzioaren monitorizazioan begirale gisa eta ur-toxikologian saiakuntza-animalia gisa erabili ohi diren muskuiluei aplika dakieken biomarkatzaile anitzeko hurbilketa erangikorra sustatuko lukete. Berrikuspen honek muskuiluen biologiari buruz eta biomarkatzaile eta euren aldakortasun naturalari buruz egun dugun ezagutzaren funtsezko oinarriak azaltzea du helburu.

HITZ GAKOAK: bibalbioak, biomarkatzaileak, monitorizazio-programak, toxikologia.

\begin{abstract}
The assessment of the marine pollution has been recognised as an immediate need for sustained management and conservation of the marine resources. Monitoring programs based on biological responses to pollutants (biomarkers) in sentinel mussels are accepted as a tool for the marine ecosystem health assessment. Due to the interactions between pollutants and natural factors or between natural factors themselves, interpretation of biological responses to pollutants can be difficult. Determining the range of natural variability in biomarkers and how such variability might influence on correct interpreting of biomarkers in the assessment of the biological effects of pollution is of mayor importance. Although first steps have been done, further research is needed to fully understand the natural variability of biomarkers. A better understanding of the natural variability of biomarkers is needed for the development of assessment guidelines, which would endorse a cost effective multi-biomarker approach applied to mussels regularly used as sentinels in marine pollution monitoring and as experimental animals in aquatic toxicology. This review aims at explaining basic foundations of mussel biology and biomarkers and the current knowledge about their natural variability.
\end{abstract}

KEYWORDS: bivalves, biomarkers, monitoring programs, toxicology.

1

*Harremanetan jartzeko/ Corresponding author: Ionan Marigómez, CBET Res. Grp., Dept. Zoology \& Animal Cell Biology, Univ. Basque Country (UPV/EHU), Sarriena auzoa, zg, 48940. Leioa, , Euskal Herria @ https://orcid.org/ 00000001-6274-541X, ionan.marigomez@ehu.eus

Nola aipatu / How to cite: Blanco-Rayón, Esther; Marigómez, Ionan; Izagirre, Urtzi. (2020). << Kutsadurari aurre egiteko muskuiluen erantzun biologikoak eta euren aldakortasun naturala >>, Ekaia, Ale berezia, xx-xx. (https://doi.org/10.1387/ekaia.21101)

Jasoa: 18 iraila, 2019; Onartua: 21 azaroa, 2019

ISSN 0214-9001-eISSN 2444-3225 / @ 2019 UPV/EHU 


\section{SARRERA}

Ozeanoak eta itsasoek biosferaren \%90-a hartzen dute barne. Beraz, lur- eta ur gezako ekosistemek baino dibertsitate biologiko handiago dute. Halaber, itsas ekosistemek klima- eta eguraldi- ereduei dagokienez zeregin nagusia dute eta ekonomi oparotasunari, giza ongizateari zein bizitza-kalitateari ekarpen itzela dakarkiete [1]. Haatik, jarduera antropogenikoek sortutako kutsadurak mundu osoko itsas ekosistemei mehatxu egiten die etengabe $[2,3,4,5$, 6]. Kostaldeko ekosistemak bereziki kaltetuak izan dira, zeren eta organismoen osasuna, biodibertsitatea eta ekosistemen funtzionamendua mehatxatzen dituzten isurketa kroniko eta isuri akzidental moduko gorabeherei aurre egiten baitiete [7]. Testuinguru honetan, itsas baliabideen kontserbazio eta kudeatze sostengarrirako ezinbesteko beharrizan gisa antzeman da itsas kutsadura ebaluatzea [7]. Hortaz, itsas ekosistemetan kutsatzaileek dituzten efektuak ebaluatzeko estrategia ezberdinak garatu dira munduan zehar, kostaldeko monitorizazioprogramak barne $[8,9,10]$. Bestalde, egun badakigu kutsadurarena ez ezik, itsas ekosistemek eta organismoek barne- eta kanpo-faktoreen eragina ere jazo dezaketeela. Esate baterako, prozesu ekologikoak zein euren arteko elkarreragina, arrantza, klima-aldaketa, habitaten aldaraztea eta eutrofizazioa estres-eragile aski ezagunak dira [8].

Monitorizazio-programa ingurumen-kalitatearen parametroen azterketa sistematiko errepikatua da, kokapen geografiko mugatuan eta zenbait urteetan zehar uretan, sedimentuetan edo eta biotan burutzen dena [11]. Itsas poluzioaren monitorizazio-programen hastapenetan uretan, sedimentuetan eta biotan egindako konposatu kimikoen azterketen bitartez antzematen zen kutsadura. Aitzitik, tresna kimiko analitikoak soilik erabiliz ingurumenean kutsatzaileak detektatu eta kuantifikatzea ez da nahikoa kutsatzaileek ekosisteman duten eragina antzemateko $[12,13,14]$. Izan ere, ingurumenean kutsatzaileak nahaste konplexu gisa agertzen dira, eta horrek biotaren gain duten toxikotasunaren ebaluatze zehatza konprometitzen du [13]. Ondorioz, Europan nagusiak diren JAMP (Joint Assessment and Monitoring Program), MED POL (Mediterranean Pollution Monitoring Programme) eta HELCOM (Baltic marine environment protection commission edo Helsinki commission) itsas monitorizazio-programetan, poluitzaileen aurrean erakutsitako konplexutasun biologiko ezberdineko erantzun biologikoak ebaluatu beharra dago [12, 15, 16, 17]. Kutsaduraren monitorizazio-programetan efektu biologikoak antzemateko erabiltzen diren organismoei "begirale" izena ipini zaie, euren artean erabilienak muskuiluak izanik [18, 19, 20, 21]. Halaber, kutsatzailei aurkako erantzun biologikoen neurri goiztiarrak "biomarkatzaile" izenaz 
bataiatu dira, itsas monitorizazio-programetan oso tresna erabiliak izanik [18, 19], bereziki muskuilu begiraleen kasuan [20, 21].

\section{MUSKUILUAK ORGANISMO BEGIRALE GISA}

Muskuiluen baliotasuna organismo begirale gisa euren ezaugarri biologiko eta ekologikoetan datza [19, 20, 22]. Jarduera metaboliko oso baxua duten animalia sesil iragazleak izanik, ehunetan dituzten poluitzaileen kontzentrazioek ingurumen kutsaduraren magnitudea zehaztasunez isla dezakete. Are gehiago, ingurumen-baldintzen tarte zabal itzela jasateko gaitasuna dute, kutsatzaile mota gehienen neurrizko kontzentrazio altuak barne. Aldi berean, ez dira ingurumen-eragilendako soraioak. Halaber, zelaian biltzea eta laborategian mantentzea erraza izateak saiakuntzan muskuiluen erabilpenaren hedatze zabala ekarri du. Ondorioz, euren biologiaz asko badakigu. Azkenik, oso hedatuta daude munduan zehar eta ikuspegi ekonomikotik ere oso garrantzitsuak dira.

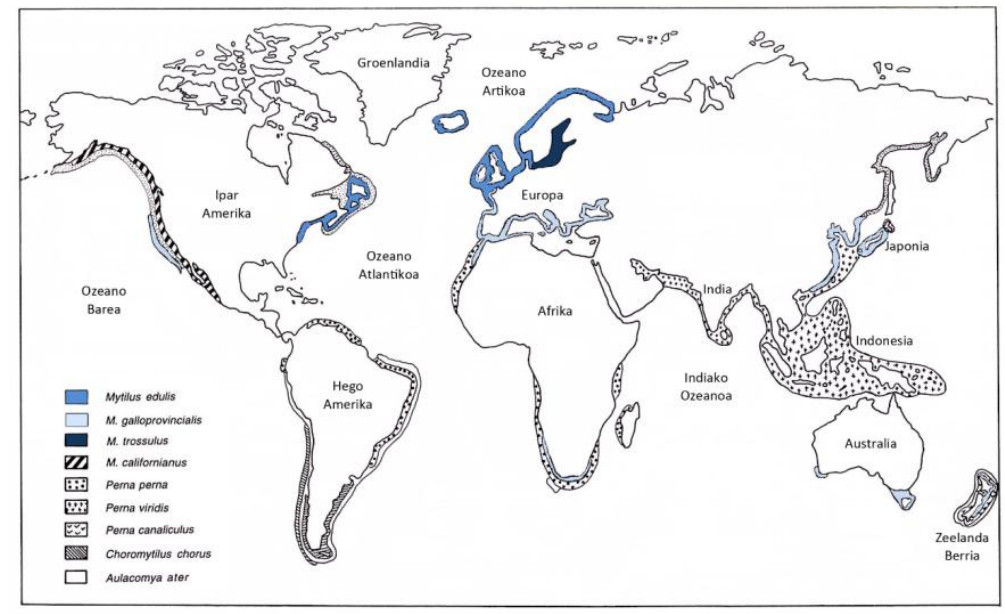

1. irudia. Ikuspegi ekonomikotiki garrantzitsuenak diren muskuiluen espezieen banaketa biogeografikoa (Gosling, 2004-tik egokituta).

Mytilus generoko muskuiluak (grezieratik, mitilos = itsas muskuilu), iparraldeko eta hego hemisferioko kostalde harritsuen eta ur hotz eta epeletako komunitateen partaide nagusien artean daude (1. irudia). Europan hiru espezie antzeman dira: M. galloprovincialis, M. edulis eta $M$. trossulus $[23,24]$. Hiru espeziek nortasun genetiko ezberdinak kontserbatu dituzte, gehien bat bakoitzari eskualde biogeografiko propio dagokiolako [26]. Hala ere, eskualde biogeografikoen arteko trantsizio eremuetan eskualde hibridoak sor daitezke aldameneko espezien artean [26, 27]. 
Mytilus spp. muskuiluen banaketa kostaldean oso zabala da; goi marearteko mailatik mareapeko mailara, itsasadar-baldintza duten eskualdetik itsas baldintzak dituztenetara, eta kostalde babestuetatik olatuen indarra bortizki jasaten duten kostaldeetara aurki daitezkeelarik [28]. Bestalde, marearteko zonaldean banaketari dagokionez, goiko hedapen-muga tenperatura moduko faktore fisikoek gobernatu ohi dute, eta behekoa gehienetan harrapariek ezartzen dute [29].

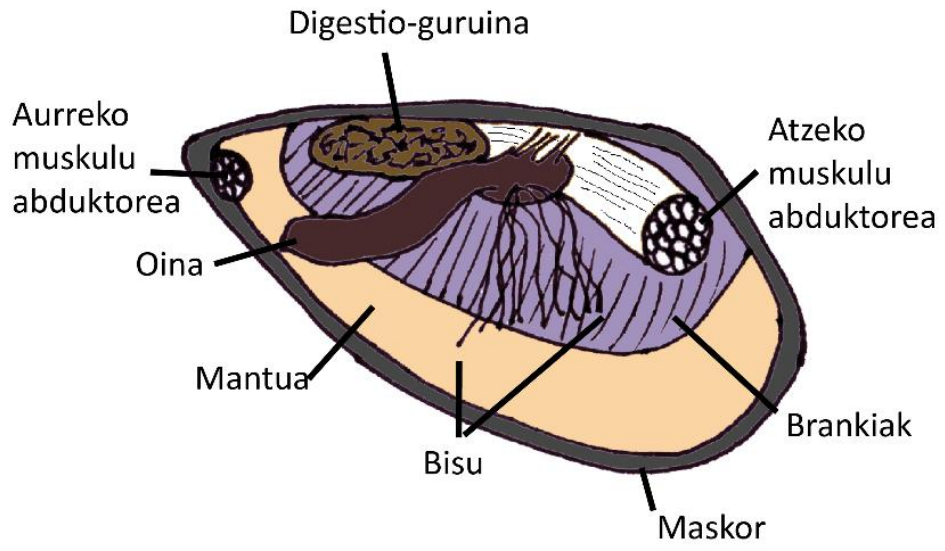

2. irudia. Mytilus sp. muskuilu baten barne-anatomiaren eskema (Blanco-Rayón, 2018-tik egokituta).

Ingurumen-osasun mailaren ebaluaketan analisi kimikoak egiteko zein kondiziofaktoreak kalkulatzeko muskuiluen haragi osoa erabili ohi da. Halaber, oina, mantua, brankiak eta digestio-guruina moduko organo ezberdinak banaka erabiltzen dira biomarkatzaileak aplikatzekotan [20].

Oinak, nolabaiteko lokomozio-gaitasuna eman diezaieke muskuiluei, gazte-etapan gehien bat (2. irudia). Oina, proportzionalki luzanga eta galtzerdi-formakoa izanik, tamaina handiko odol-gunea inguratuz paratutako muskulu zirkular eta longitudinaleko geruzaz osatuta dago (3A eta 3B irudiak). Bertan erantzun immunitarioaren eragile nagusiak izanik askotan toxikologian aztergai diren hemozitoak (odol-zelulak) ugariak dira. 

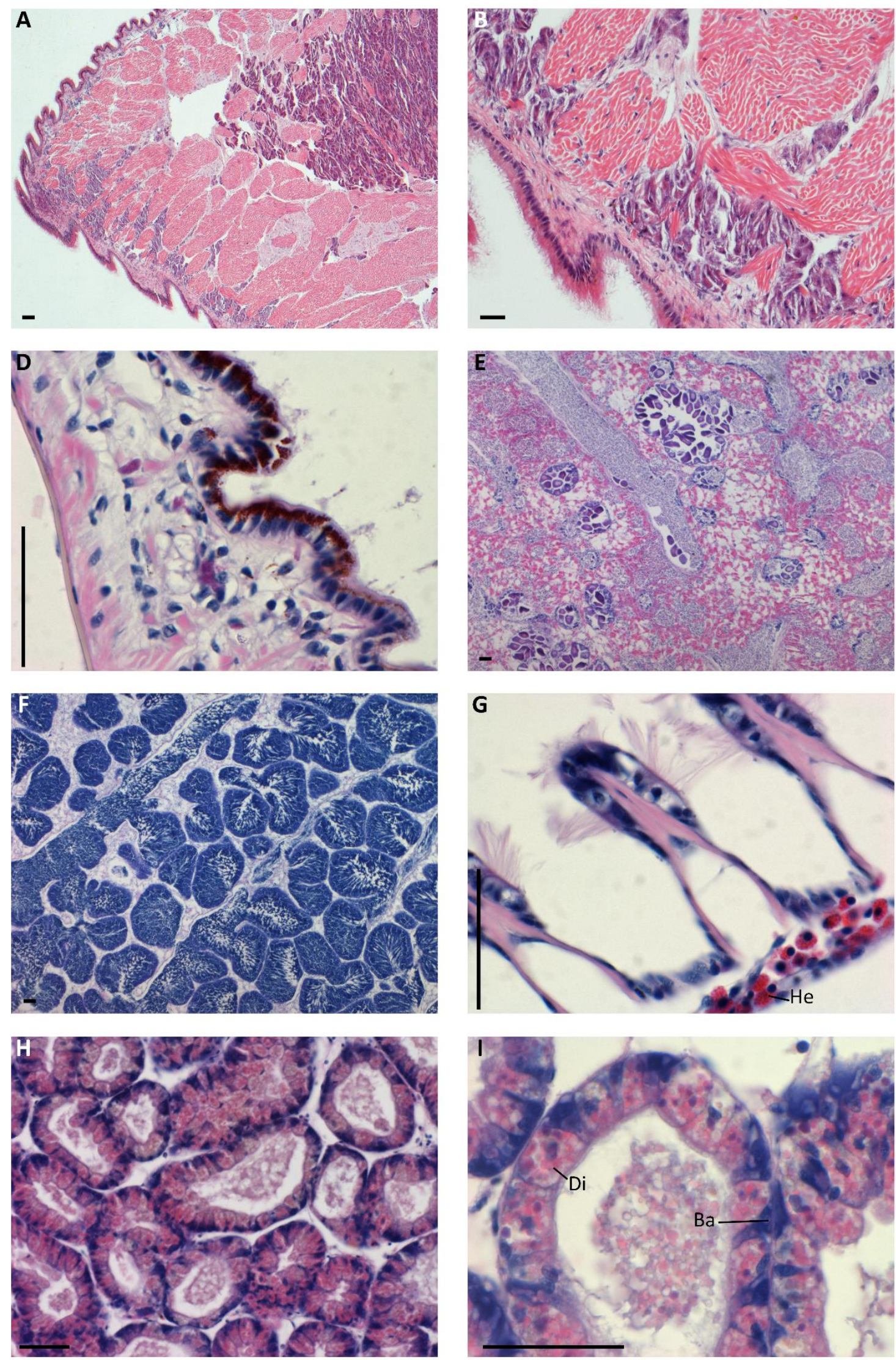

3. irudia. Hematoxilina-eosinaz tindatutako M. galloprovincialis muskuiluaren ehunak. Eskala: $50 \mu \mathrm{m}$. A, B) Oina. D) Gonada emea. E) Gonada arra. F) Mantua. G) Brankiak. H, I) Digestio-guruina. He: hemozitoa; Ba: zelula basofilikoa; Di: digestio-zelula (Blanco-Rayón, 2018-tik egokituta). 
Bibalbioetan, maskorraren barruan animalia zeharo ixten duten bi ehun-lobuluk osatzen dute mantua (2. irudia). Bertan oso garatuta dauden odol-hodiak, nerbioak zein muskuluak daude, ertzen ondoan bereziki. Mantuaren ertzek, muskuiluari eguzki-erradiazioaren efektu kaltegarriekiko babesa ematen dion pigmentazio iluna dute (3C irudia) [30]. Mantu barruan gametoak garatzen dira, gerora mantu barrunberantz husten diren binakako gonoduktuetaraino ziliodun kanaletan zehar garraiatzen direnak (3D eta $3 \mathrm{E}$ irudiak). Errunaldian gametoak askatutakoan mantua mehe eta gardena da. Kutsaduraren monitorizazio-programetan jasotzen diren datuen artean gametoen garapenari dagozkienak garrantzitsuak dira, muskuiluaren osasun eta fisiologiari buruz funtsezko informazioa eman baitezakete [31, 32]. Informazio horrek biomarkatzaileak interpretatzeko laguntza eskaintzeaz gain, toxikotasunari buruzko datu espezifikoak ere eman ditzake. Adibidez, sexu-ratioen aldaketek ekosisteman disruptore endokrinoen poluzioa egon zitekeela adieraz lezakete [33]. Bibalbioetan ugal-zikloaren bidea ebaluatzeko metodorik fidagarrienak gonadaren gertakina histologikoetan datza [34]; gertakin horietan gonadaren garapen-faseak identifika daitezke Kim eta lankideen [35] metodoa oinarri hartuz egokitutako honako irizpide hauek erabiliz (4. irudia):

- Fasea I. Gonada atsedenaldian. Fase honek heldutasunera ailegatu ez diren zein errute burutu duten muskuiluak hartzen ditu barne, zeintzuetan gametorik gabeko gonadafolikulu garatu gabeak edo gutxi garatutakok baitaude.

- Fasea II. Gonada gametogeneniko goiztiarra. Gonada, gehien bat gametogenesiaren etapa goiztiarrean dauden gametoz osatuta dago; hau da, hozi-epitelioari atxikitako oozito txiki ugariz emeetan, eta espermatogoniaz zein espermatozitoaz arreetan.

- Fasea III. Gonada gametogeneniko aurreratua. Fase honetan gonadak oro har masa emendatu du, ehun konektiboan metatutako erreserben kontura. Gametogenesiak bizkor egiten du aurrera, folikulu bakoitzaren erdia gameto helduz eta beste erdia gametogenesia goiztiarrean dauden gametoz osatuta egonik. Gonada guztiz heldua deneko kondizioan betetzen duen ehun-eremuaren erdia beteta agertzen da gutxi gorabehera.

- Fasea IV. Gonada heldua. Fase honetan gonada guztiz heldua izatera iritsi da, mantuko ehun konektiboa oso urria delarik. Oozitoak trinkotu egin dira itxura poligonala erakutsiz; folikulu arrak berriz arrotuta agertzen dira, eta morfologikoki helduak diruditen espermatozoidez beteta daude.

- Fasea V. Errunaldia. Gonada-folikuluak partzialki gametoz hustuta ageri dira. 
- Fasea VI. Errunaldi osteko fasea. Gonada-folikuluek gameto gutxi edota hondargametoak dituzte, besterik ez.

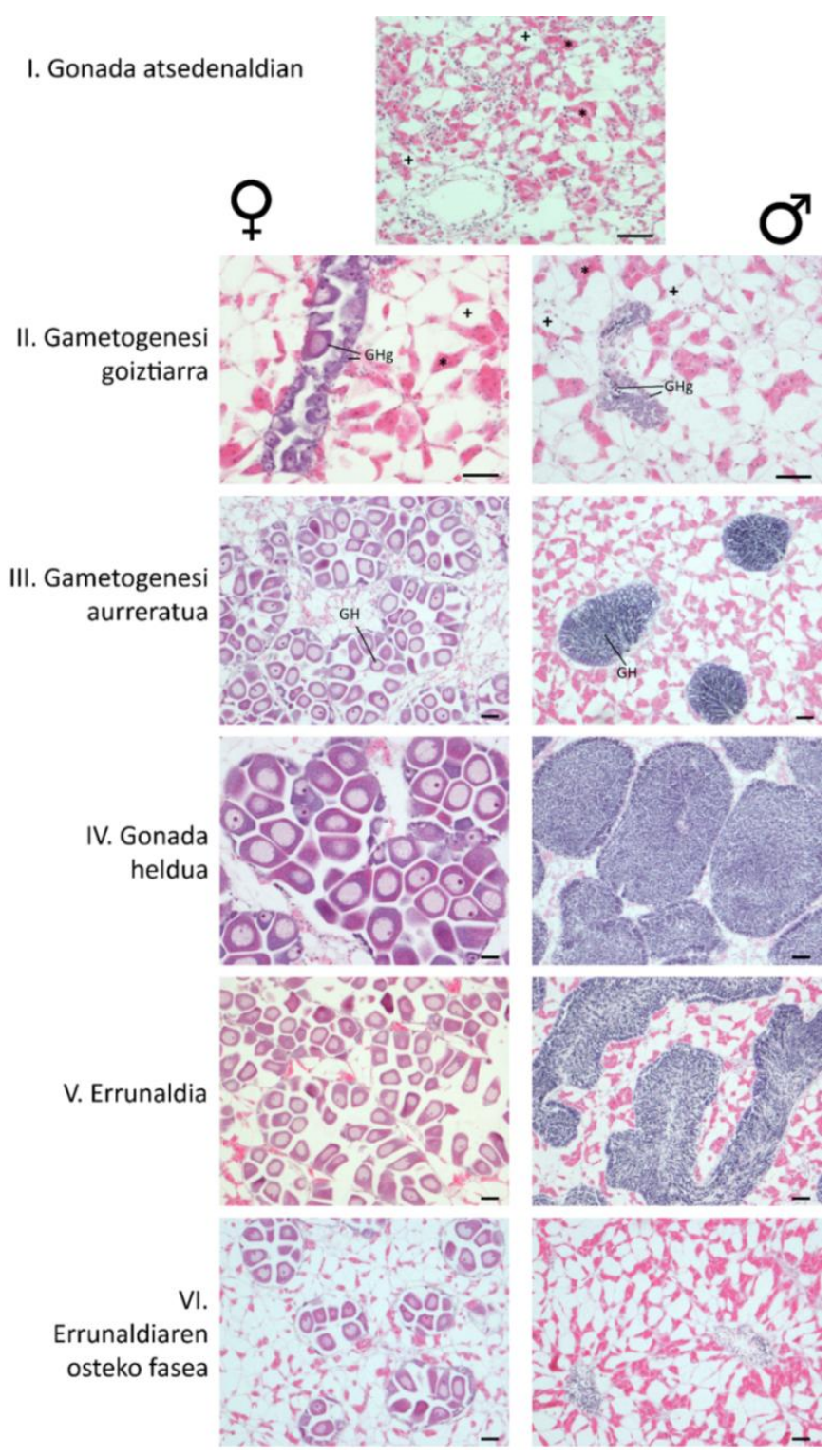

4. irudia. Hematoxilina-eosinaz tindatutako M. galloprovincialis muskuiluaren gonada eme eta arra garapen gametogenikoaren fase desberdinak erakutsiz. Eskala: $50 \mu \mathrm{m} .+$ : konektiboko besikulazelulak, *: zelula adipogranularrak, GHg: gameto heldugabeak, GH: gameto helduak.(Blanco-Rayón, 2018-tik egokituta).

Ugal-zikloak malgutasun puntu bat dauka, eta geografikoki urrun ez dauden muskuiluen populazioen artean zein populazio baten barruan urteen artean desberdintasunak aurki daitezke kasuz kasu, tenperatura eta jakien eskuragarritasun moduko ingurumen-faktoreen arabera. Kutsatzaileek berriz haratago doazen aldaketak sor ditzakete ugal-zikloan [33]. Oro har, eskualde epeleko Mytilus spp. muskuiluen gonadaren garapena neguaren bukaeran edo udaberrian hasten da, uraren tenperatura eta jakien eskuragarritasuna areagotzearen eskutik, 
eta errunaldia udaberri amaieran gertatzen da [19, 28]. Euskal Kostaldeko $M$. galloprovincialis populazioen kasuan, gonada gametogeniko aurreratu zein gonada heldua faseetara jada neguan zehar iritsi ahal da; errunaldia, bere aldetik, udaberri osoan zehar eta nolabait ere udan gerta daiteke $[33,36]$. Nahiko jaki eskura egotekotan errunaldia berriz gerta daiteke uda berantiarrean, baina oro har ordurako muskuilu gehienek euren gonada birxurgatu dute erreserba-ehuna garatzearekin batera; eta uda berantiarrean jada ziklo gametogeniko berriari ekin zaio $[33,37,38]$. Garapen gametogenikoaren lekua izateaz gain mantua ere bada gune nagusia elikagaien erreserbak gordetzeko, glukogenoa gehien bat [28]. Erreserba horiek udan lortzen dira, eta udazken eta neguan gametoak sortzeko erabiltzen dira [19, 28].

Plankton, itsas uretan aske flotatzen duten beste itsasoko organismo mikroskopiko eta detritu-partikulez elikatzen dira muskuiluak. Ktenidio izenaz ere ezagutuak, brankiak filibrankio motakoak dira, lauak, homorrabdikoak eta tolesgabeak hain zuzen (2. irudiak). Brankiek arnas-funtzioaz gain elikadura-funtzioa ere badute. Euren azalera handiko azal meheari esker, eta odolaren hornidura aberatsari esker gas-trukeari ekiteko egitura egokia dute (3. irudia). Arnas-funtzioa dela-eta, metabolismo oxidatibo zein babes antioxidatzailea oso prozesu garrantzitsuak dira organo honetan; gainera brankiak, uretan dauden poluitzaileei aurre egiten dien lehen organoa izanik, disolbatutako poluitzaileen sarbide nagusia direla antzeman da [39]. Hortaz, euren jarduera entzimatiko batzuk oso erabiliak dira biomarkatzaile gisa, poluitzaileei aurka babes antioxidatzailean parte hartzen duten entzimen jardueren aldaketak esaterako [20]. Bestalde, esan bezala, brankiek ere elikadura-funtzioa badute, eta bertan jakiaren harrera hasten da. Izatez, euren traktu ziliodunez baliatuz brankiek partikula zilio latero-frontaletan atxikitzen dira eta hortik aurreko lameletarantz garraiatzen dira, mukian sartuta eta aurreko zilioen mugimenduari esker [28] (2. eta 3G irudiak). Hautatutako partikula esekiak ahora sartzen dira ezpain-palpoen oinarrian dagoen aho-ildoan zehar, eta hestegorria iragan ostean urdailera eta digestio-guruinera iristen dira, bertan digestioa gauza dadin. Digestioa bi fasetan ematen da: 1., zelulaz kanpoko digestioa, urdailean ematen dena estilo kristalinoaren ekintza mekaniko eta entzimatikoaren ondorioz; eta 2., zelula barruko digestioa, digestio-guruinaren digestio-zelulen sistema endo-lisosomikoan ematen dena [40, 41].

Bibalbioetan urdaila eta digestio-guruina ziliodun digestio-konduktu adarkatuen bidez komunikatuta daude (5. irudia). Digestio-konduktuen barnean bi norabideko fluxua dago (6. irudia). Alde baterantz jakiak urdailetik digestio-guruinerantz doaz bertan zelulek jakien barne-digestioa eta barne-mediorantz elikagaien xurgapena burutzeko: beste alderantz, 
digestio-guruina sortutako hondakinak (ingestio eta digestio prozesuetatik eratorritako hondar organiko endogeno eta exogenoak) urdailerantz eta gerora hesterantz kanporatzen dira.

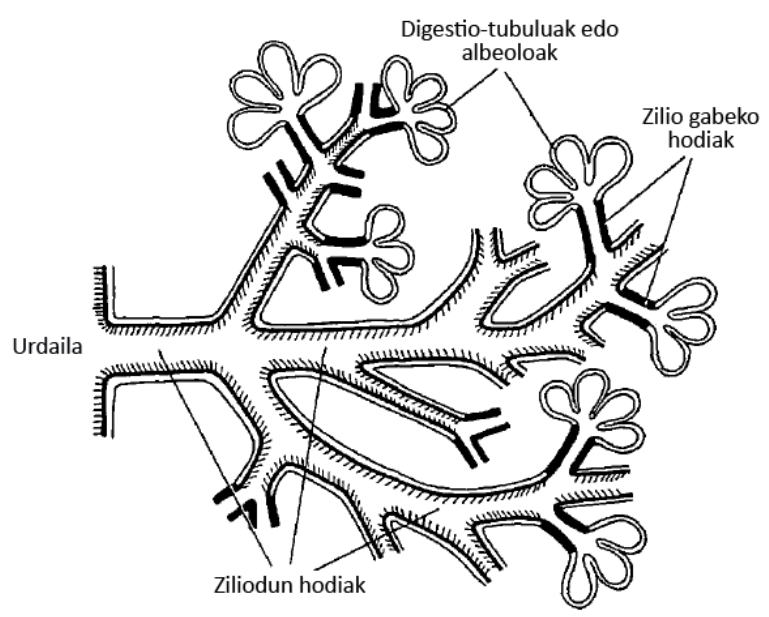

5. irudia. Bibalbioen digestio-guruinaren digestio-konduktuen sistema (Owen, 1955-tik egokituta).

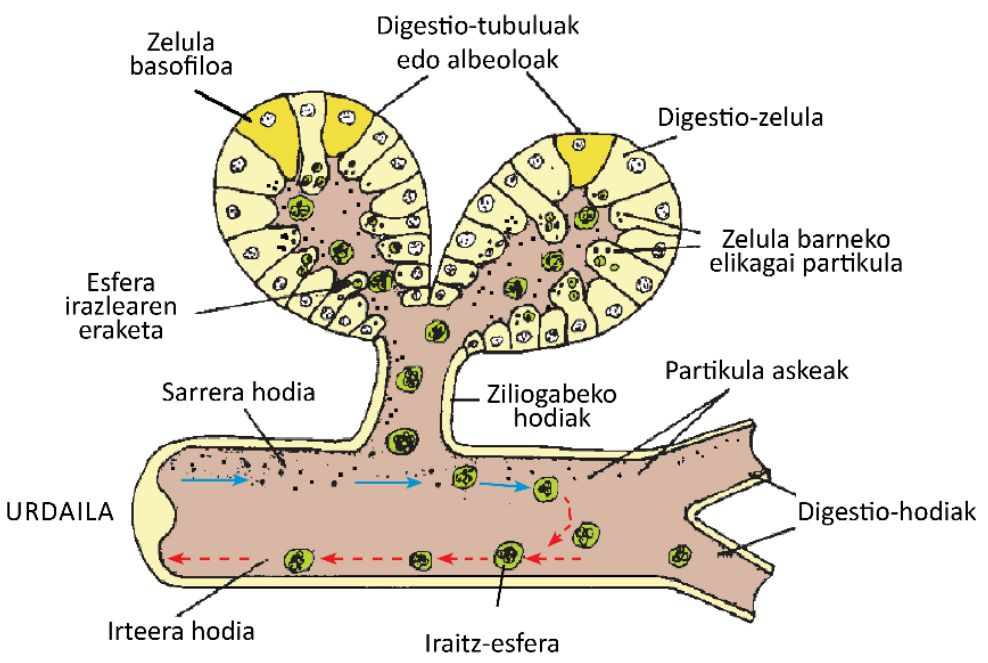

6. irudia. Bibalbioen digestio-guruinaren ebakidura eskematikoa (Owen, 1955-tik egokituta).

Digestio-guruinak adenomero egitura du eta beren epitelioan oro har 2 zelula-mota antzeman dira, digestio-zelula eta zelula basofilikoa hain zuzen ere (7. irudia) [40]. Baldintza normaletan itxura prismatikoa duen digestio-zelula ugariena da [42, 43, 44]. Zelula-mota honek oso sistema endo-lisosomiko garatua du, eta urdailetik partzialki digerituta datozen jakien zelula barruko digestioa du funtzio nagusi [40, 45]. Zelula barruko digestio hori lisosometan gertatzen da. Lisosomak hidrolasa azidoz eta beste entzima hidrolitikoz hornituta daude, zelula eukariotiko ia guztietan zelula barruko digestioan aritzen diren organulu zelular multifuntzionalak direlarik [46]. Jakien eta bestelako molekulen zelula barruko digestioaz 
gain, zelularen birziklapen autofagikoa dela-eta, soberazko eta kaltetutako organulu eta osagai zelularren degradazioan ere jarduten dute lisosomek [47, 48, 49].

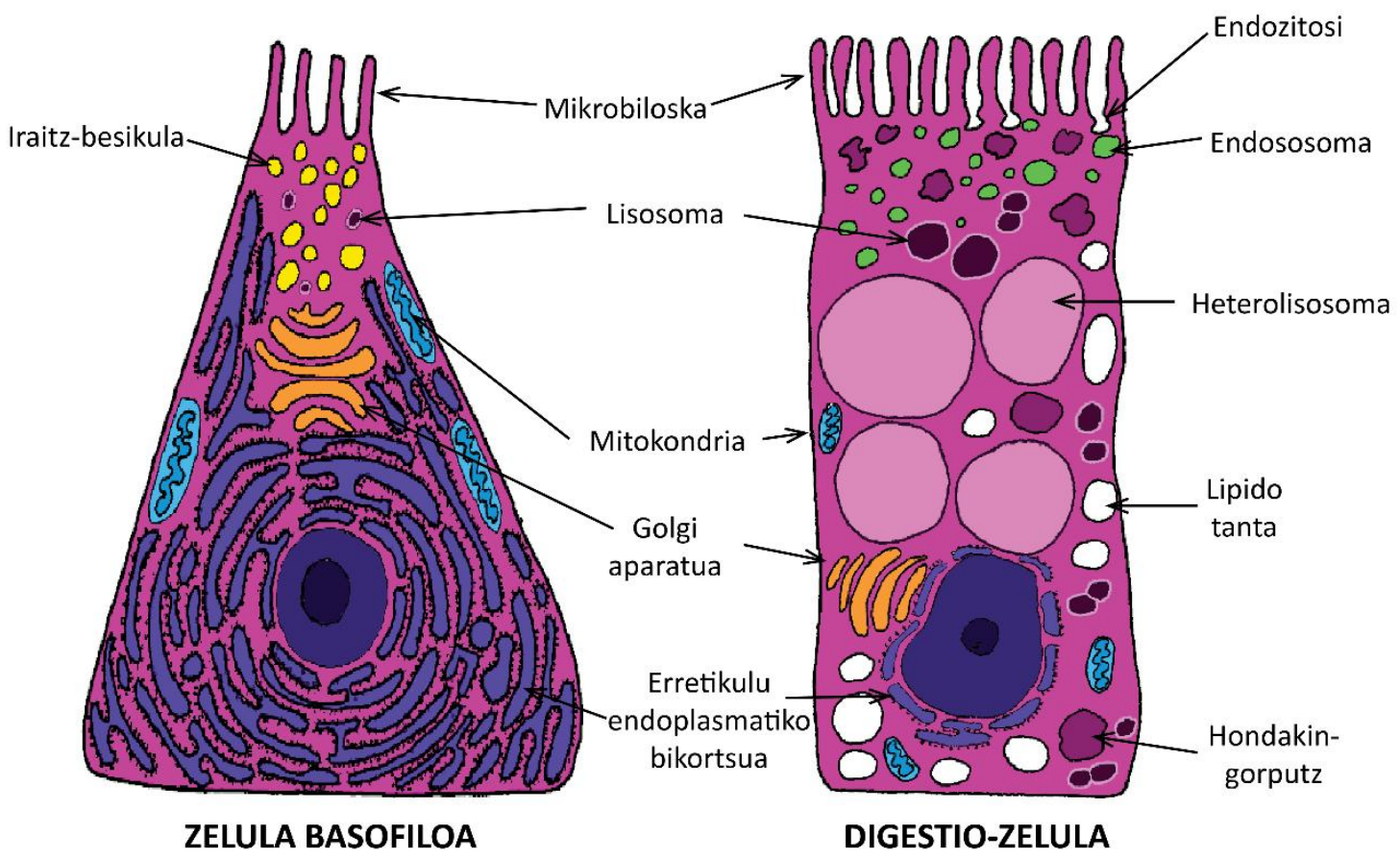

7. irudia. Bibalbioen digestio- epitelioan dauden bi zelulen ultrastrukturaren eskema (Blanco-Rayón, 2018-tik eta Owen, 1973-etik egokituta).

Bibalbio guztietan morfologikoki lau digestio-faseei dagozkien lau epitelio-mota bereiz daitezke [50, 51]: atseden-fasea (mota I); xurgapen-fasea (mota II); desintegrazio-fasea (mota III); eta birsotze-fasea (mota IV) (8. irudia). Marearteko muskuiluen kasuan, digestioguruinaren digestio-zelula gehienak sinkronizatuta daude eta zelulen sinkronia hori itsasaldien erritmoari (eta jakien eskuragarritasunari) estuki lotuta agertzen da. 


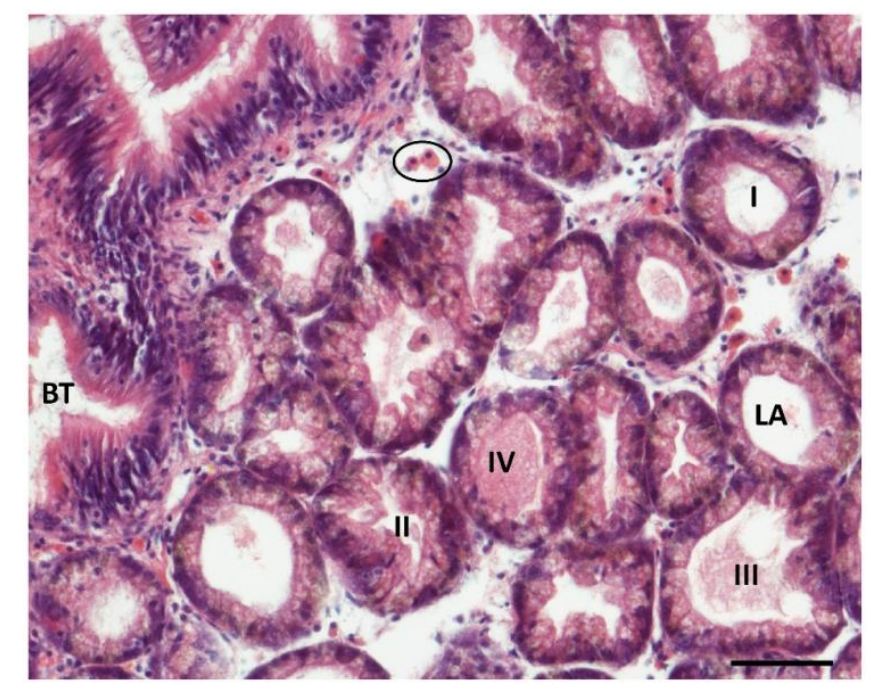

8. irudia. Hematoxilina-eosinaz tindatutako M. galloprovincialis muskuiluen digestio-guruinaren ebakin histologikoa. Eskala: $50 \mu \mathrm{m}$. I: atseden-fasea, II: xurgapen-fasea, III: desintegrazio-fasea, eta

IV: birsortze-fasea. BT: bigarren mailako digestio-konduktua. LA: digestio-albeoloa. Zirkulua: hemozitoak. (Blanco-Rayón, 2018-tik egokituta).

Zelula basofilikoak itxura piramidala du (7. irudia), eta erretikulu endoplasmatiko bikortsuz (EEB) eta Golgi gorputzez beteta du zitoplasma, beren zeregin nagusia proteinen sintesia dela iradokiz. Zenbait ikerlanek diotenez, zelula-mota honek entzimak jariatuko lituzke adenomeroaren argirantz, bertan zelulaz kanpoko digestioa gerta dadin [52]. Haatik, digestio-zelulak Golgi aparatua eskasa du eta beren sistema endo-lisosomiko handiak badu hidrolasen premia itzela denbora tarte txikian [53, 54]. Hori dela-eta, digestio-zelula hidrolasez behar bezala hornitzeko zelula basofilikoak entzima lisosomikoak edo euren aitzindariak pasatuko lizkioke, eraendutako zelularteko entzimen transferentzia bidez [53, 54]. Digestio-prozesuaz gain, xenobiotikoen detoxifikazio- eta erauzketa-prozesuan ere dihardu digestio-guruinak, eta baita poluitzaileen metaketan ere. Horregatik, digestio-guruina itu-ehun nagusien artean dago toxikologia arloan, batik bat polutzaileekiko erantzun biologiko neurgarri goiztiarrak (biomarkatzaileak) aplikatzekotan [20]. Hori dela-eta, digestio-prozesua eta digestio-guruinaren funtzionamendua ulertzea ezinbestekoa da biomarkatzaileak hobeto interpretatzeko.

\section{BIOMARKATZAILEAK}

Biomarkatzaile kontzeptua aurrenekoz medikuntz diagnostikoan aplikatu zen, gizakien kondizio edo gaixotasun jakin baten adierazle gisa [55]; eta 1990.eko hamarkada hasieran erakargarria oso bilakatu zen ingurumen-toxikologia arloan [56, 57]. Horren ondorioz, ingurumen-biomarkatzaileei aipamena egin dieten argitalpen zientifikoen kopurua urtero 
\%12-a hazten joan da 2000.ekoz geroztik, eta Web of Science (2019) plataformaren arabera munduan 1000 ikerlan baino gehiago argitaratzen ari dira urtero gaur egun (9. irudia).

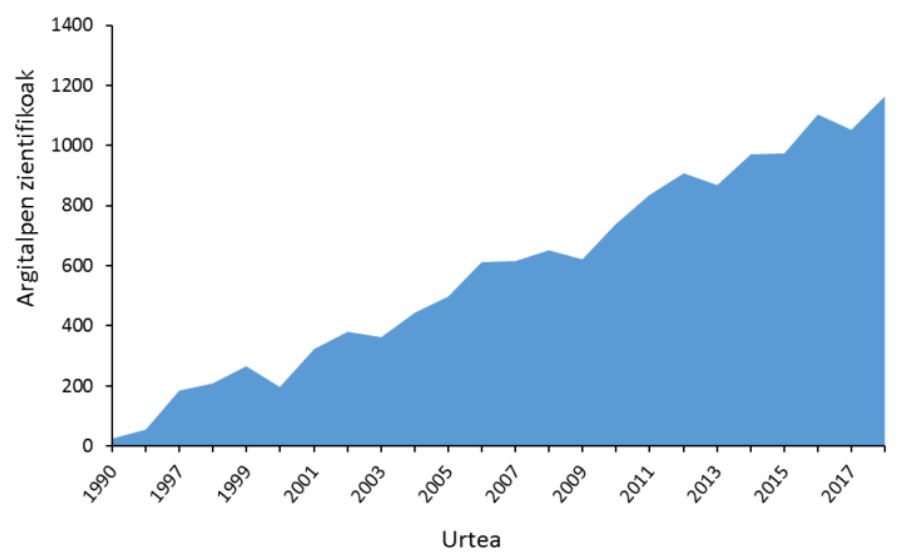

9. irudia. Urtero "ingurumen biomarkatzaile" hitz gakoak dituzten argitalpen zientifikoen zenbakia 1990-tik 2018-ra (Web ofScience, 15/07/2019).

Ingurumen-toxikologiaren arloan biomarkatzaileak maila biokimiko, maila zelular edo ehun-mailan erdietsitako neurriak dira, zeintzuek poluitzaileen presentzia (esposiziobiomarkatzaileak) edo eta eurei aurre egiteko erantzunaren magnitudea (eraginbiomarkatzaileak) adieraz baititzakete $[20,56]$. Alerta goiztiarreko erantzun horiek konplexutasun biologiko maila baxuetan gertatzen dira aurki eta antolakuntza biologiko maila konplexuagotan poluitzaileek epe luzean eduki ditzaken eragina iragartzeko abagunea eman diezagukete (10. A irudia). Biomarkatzaile bakar batek berez bere aldetik poluitzaileen presentziaz zein horren ondorio biologikoez informazio partziala baino ematen ez duenez, maila biologiko ezberdineko biomarkatzaile-multzoa erabiltzea gomendatu da [21]. 
A

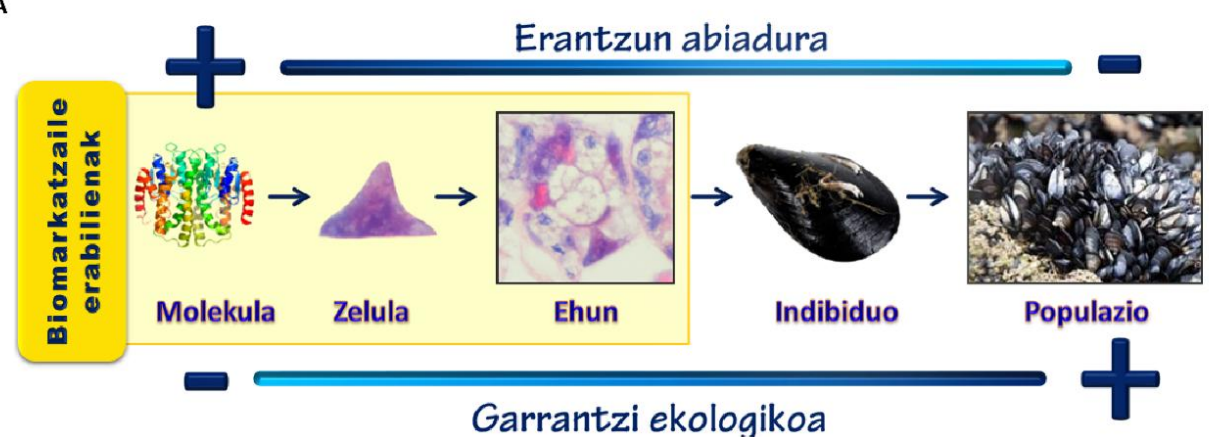

B

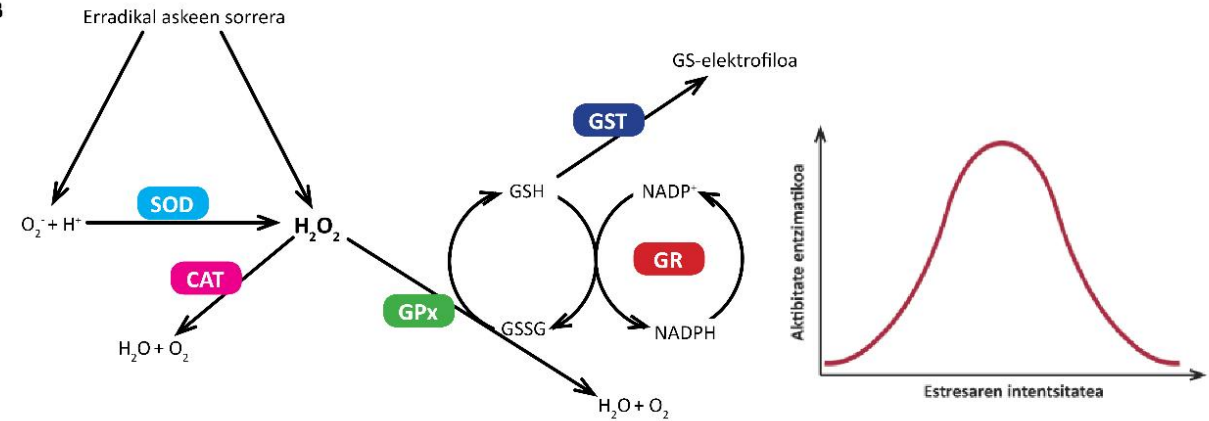

D

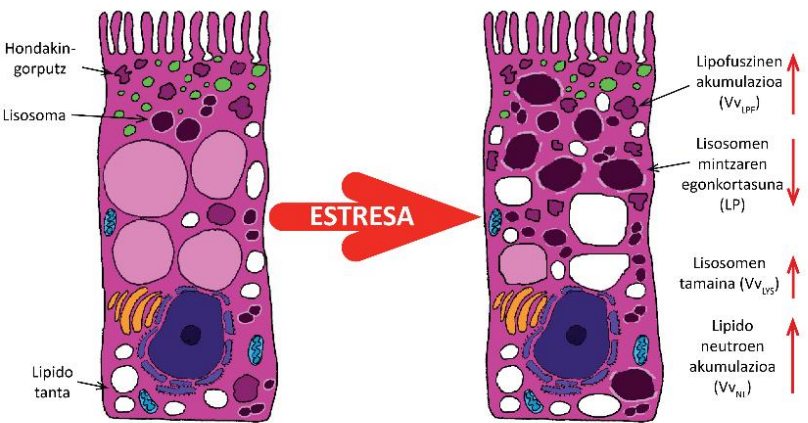

E

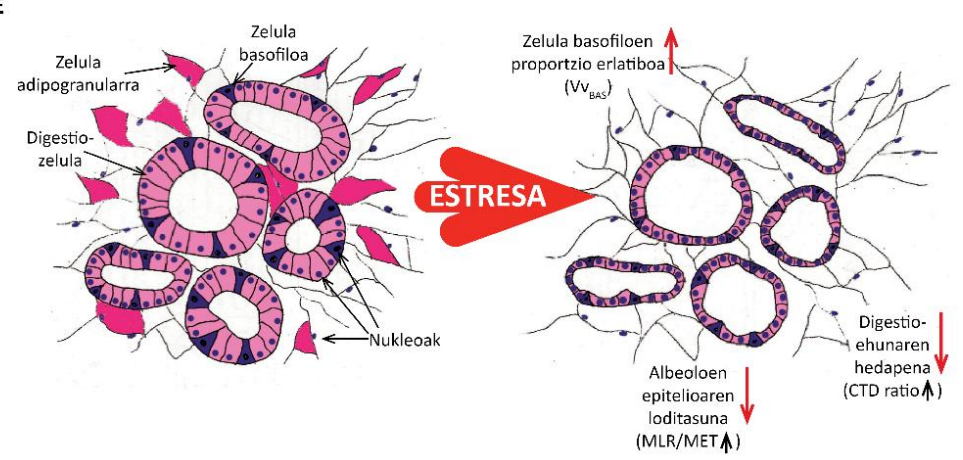

10. irudia. Biomarkatzaileak. A: erantzun biologikoen arteko lotura, konplexutasun biologiko maila desberdinetan eta beraien garrantzia denbora-eskalan. B: entzima antioxidatzaileen elkarlana integratuaren eskema sinplifikatua eta jarduera-estresaren arteko erlazioaren dinamika (Storey 1996-tik egokituta). Laburdurak: CAT, katalasa; GPx, glutation peroxidasak; GR, glutation erreduktasa; GSH, glutation; GSSG, glutation bisulfuroa; GST, glutation-S-transferasa; $\mathrm{NADP}^{+}$, nikotinamida adenina binukleotido fosfato; NADPH, nikotinamida adenina binukleotido fosfato erreduzituta; SOD, superoxido dismutasak . D: digestio-zelulako lisosomen erantzuna estresaren aurrean eta bere neurriak (Blanco-Rayón, 2018-tik egokituta). Laburdurak: LP, labililizazio-aldia; $\mathrm{Vv}_{\mathrm{LPF}}$, lipofuszinen bolumen dentsitatea; $\mathrm{V}_{\mathrm{LYS}}$, lisosomen bolumen dentsitatea; $\mathrm{V}_{\mathrm{NL}}$, lipido neutroen bolumen dentsitatea. E: ehun-mailan estresaren aurrean digestio-guruinean ematen diren erantzun

biologikoak eta euren neurriak (Blanco-Rayón, 2018-tik egokituta). Laburdurak: CTD ratio, ehun konektibo/dibertikulu; MLR/MET, batez besteko lumeneko erradio/batez besteko epitelio-lodiera; $\mathrm{Vv}_{\mathrm{BAS}}$, zelula basofilikoen bolumen dentsitatea. 


\subsection{Entzima antioxidatzaileak}

Poluitzaile gehienek mehatxu oxidatzaile eta babes antioxidatzaileen arteko oreka zelularra alda dezakete, gaitasun antoxidatzailea murriztuz ala emendatuz. Itsas animalietan, eta muskuiluetan bereziki, babes antoxidatzailearen entzimek izugarrizko gaitasuna dute estres anitzen aurrean erantzuteko. Beraz, estres oxidatibo biomarkatzaile gisa askotan aplikatu dira. Entzima horiek elkarlanari ekiten diote era integratuan (10. B irudia) [57]: superoxido dismutasak (SOD) superoxido erradikalak katabolizatzen ditu, eta katalasak (CAT) eta glutation peroxidasak (GPx) hidrogeno peroxidoa eta hidroperoxidoak degradatzen dituzte. Bestalde, babes antoxidatzailearen entzima sekundarioen artean glutationaren metabolismokoak ditugu. Glutation-S-transferasak (GST) xenobiotiko nukleofilikoak zein oxigeno erradikal askeek kaltetutako osagai zelularrak detoxifikatzen ditu glutation erreduzituaz konjugatuz. NADPH menpeko glutation erreduktasak (GR) GPx eta GST-rako GSH substratuaren karga berriz betetzen du glutation oxidatutik abiatuta. Estres oxidatiboak kalte oxidatiboa ekar dezake; hau da, oxigeno erradikal askeen erasoak sortutako kalte biomolekularra, aldarazitako lipido eta proteina ez-funtzionalak sor ditzakeena. Kalte oxidatiboaren adierazgarri ezagunenak malonaldeidoaren (MAD) metaketa eta lipofuszinen (LPF) metaketa dira. Izan ere, estres oxidatiboaren egoeretan funtzio zelularrak galtzearen eragile nagusia lipidoen peroxidazioa da, dirudienez [58].

\subsection{Erantzun lisosomikoak}

Erantzun lisosomikoak oso erabiliak dira efektu biomarkatzaile gisa, muskuilu eta beste moluskuetan gehien bat $[5,20,21,23,40]$. Jakien zelula barruko digestioaz eta prozesu autofagikoez gain $[23,59]$, digestio-zelulen lisosomek zeregina garrantzitsua dute konposatu toxikoei aurre egiteko, poluitzaileak bahituz eta metatuz. Ingurumen-estresaren aurrean lisosomek dituzten erantzunak hiru kategoria nagusietan sailka daitezke (10. D irudia): (a) lisosomen mintza ezegonkortzea; (b) lisosomen tamaina emendatzea; eta (c) aldaketak lisosomen edukinean (adb., lipido neutro asegabeen metaketa). Erantzun horien neurriak mikroskopioan kuantifika daiteke [50, 54, 55, 60]. Adibidez, lisosomen bolumen dentsitatea $\left(\mathrm{Vv}_{\mathrm{LYS}}\right)$, azalerazko dentsitatea $\left(\mathrm{Sv}_{\mathrm{LYS}}\right)$, azalera/bolumena erlazioa $\left(\mathrm{S} / \mathrm{V}_{\mathrm{LYS}}\right)$, eta dentsitate numerikoa $\left(\mathrm{Nv}_{\mathrm{LYS}}\right)$ izeneko parametro estereologikoak neurtuz. Halaber, mintzaren egonkortasuna mikroskopioan egiten den saio funtzionalaren bidez neurtzen da, labililizazioaldia (LP) parametroa kalkulatuz. LP altua denean mintza egonkorra dena badakigu; baxua denean berriz mintza ezegonkorra. 


\subsection{Ehun-mailako biomarkatzaileak}

Azterketa histopatologiekin batera, digestio-guruinaren epitelioan konposizio zelularrean ager daitezkeen aldaketak eta epitelio-mehetze moduko adenomeroaren egituraren aldaketak tresna oso lagungarriak dira ekosistemen osasun egoeraren asalduren ebaluazioan $[6,20,43$, 44]. Esaterako, egoera fisiologiko normaletan zelula ugarienak epitelioan digestio-zelulak dira; estres-egoeretan berriz zelula basofilikoak (10. E irudia). Progresioa mikroskopia digitalez kuantifika daiteke, zelula basofilikoen bolumen dentsitatea $\left(\mathrm{V}_{\mathrm{BAS}}\right)$ parametro estereologikoa neurtuz [43, 44]. Era berean, epitelioaren mehetze edo atrofia arras ongi dokumentatuta dago estresatutako moluskuetan (10. E irudia), eta batez besteko epiteliolodiera gisa (MET) neurtu ohi da [6, 20, 60]. Digestio-guruina oso ehun dinamikoa eta plastikoa da. Izaera dinamiko horri lotuta epitelio-mehetzea ingurumen-estresaren aurrean egindako erantzun ez-espezifiko, induzigarri eta itzulgaitza dugu, bestelako patologia edo efektu fisiologikoen aitzindaritzat antzeman dena [43, 44, 61].

\section{NAHASTE-FAKTOREAK ETA JARDUNBIDE ERABILGARRI EGOKIENAK}

Poluitzaile eta faktore naturalen arteko elkarreraginek edota faktore naturalen artekoek poluitzailei aurre egiteko erantzun biologikoen interprezazioaren fidagarritasuna kolokan jarri dezakete monitorizazio-programetan. Biomarkatzaileen aldakortasun naturalaren tarteak zeintzuk diren zein aldakortasun horrek biomarkatzaileen interpretazio zuzena nola eragin dezaketen antzemateak garrantzi ukaezina du [19, 59, 62].

\subsection{Muskuiluen biologia orokorrari lotutako aldakortasun iturri intrintsekoak}

Europan hiru Mytilus spp espezie ezberdinak erabili dira zentinela gisa kutsaduraren monitorizazio-programetan, eskualdearen latitudearen arabera: M. galloprovincialis (Lmk.) hegoaldean, M. edulis (Lmk.) iparraldean eta M. trossulus (Gould) Baltikoan. Eta ikerketa gutxi badira ere, jakin badakigu espezie horiek polutzaileei aurrean erakutsitako erantzun biologikoak desberdinak izan daitezkeena [26, 27]; adibidez, genotoxizitatean [32], ugalzikloan [63] eta lisosomen erantzunetan [28] jada deskribatu den bezala. Hori dela eta, muskuiluen espezieak poluitzailei aurre egiteko erantzun biologikoen aldakortasun iturria izan daiteke Europa mailako eskala handiko poluzioaren monitorizazio-programetan. Tamalez, Mytilus generoko espezie ezberdinak ezin dira errez bereizi gene-identifikaziorik gabe. Gainera, espezien arteko hibridazioa arrunta da eta askotan espezie ezberdinen aleak eta ale hibridoak leku berean nahastuta ager daitezke. Beraz, Mytilus espezieko muskuiluak begirale 
gisa erabiltzen direnean efektu biologikoen jarraipenerako, espezieak identifikatzea oso gomendagarria da, behintzat populazioa mailan [62].

Bestalde, muskuiluen tamaina eta adina (estuki lotuta dauden ezaugarriak), sexua eta ugal-zikloa biomarkatzaileen nahaste-faktore erabakigarriak izan daitezke. Oro har, kutsaduraren monitorizazio-programetan kontsentsuzko tamainako muskuiluak erabili dira; Europan 3.5-4.5 cm-ko luzera dutenak, hain zuzen. Aldiz, tamaina bera eduki arren oso adin desberdinekoa izan daitezke leku desberdinetako muskuiluak. Adibidez, Euskal Kostaldeko 10-12 urteko eta Galiziako 4-6 urteko muskuiluek tamaina bera dute [64]. Tamalez biomarkatzaileak eta euren erantzunkortasuna oso desberdina izan daiteke muskuiluaren tamaina eta adinaren arabera, estres oxidatiboari aurre egiteko babes-entzimen jardueran, biomarkatzaile lisosomikoetan eta ehun-mailako biomarkatzaileetan (adb., histopatologian eta parasitazioan) jada demostratu denez [64]. Arrainen kasuan sexua biomarkatzaileen nahastefaktorea aski ezaguna den arren [20] muskuiluen kasuan sexuak eduki lezaken eragina gutxi ikertu da. Ikerlan batzuk heldugabe, eme eta arren artean desberdintasunak aurkitu dituzte kutsatzaileak metatzeko gaitasunean, metabolismoan eta profil proteomikoetan eragindako aldaketetan, esaterako [65-67]. Aitzitik, beste ikerketa batzuk ez dute aurkitu sexuen arteko desberdintasunak zenbait biomarkatzaileri dagokienez [60, 68, 69]. Ugal-zikloa ere aintzat hartu behar da. Lisosomen mintza ezegonkortzea udan gertatzen diren gametogenesiaren azken faseei zein errunaldiari loturiko estres-egoerarekin erlazionatu izan da $M$. galloprovincialis muskuiluan [38, 70]. Halaber, lipido neutroen zelula barruko metaketa jakien eskuragarritasunarekin eta gametoen garapenarekin lotuta dago, udan eta udazkenean beste sasoietan baino handiagoa izanik $[36,71]$.

\subsection{Ingurumen-aldagaiei lotutako aldakortasun naturala: tenperatura eta gazitasuna}

Biomarkatzaileen gain tenperaturak eduki dezakeen eragina ikertzeko zenbait laborategiko esperimentu burutu egin dira muskuiluak aztergai $[36,72]$. Esaterako, epe luzez tenperatura altuetan mantendu ostean, CAT, GPx, GR eta GST entzimen jarduera emendatzen da digestio-guruinean eta brankietan, eta metabolismo anaerobioa oro har areagotzen da [36, 72, 73]. Halaber, digestio-zelulen lisosomak handiagotzen dira eta euren mintza ezegonkortzen da [36]. Era berean, zenbait ikerlanek biomarkatzaile biokimiko eta lisosomikoen gain gazitasunaren aldaketek eduki dezaketen eragina aztertu dute. Gazitasunaren igoerak CAT jarduera emendatzen du digestio-guruinean eta brankietan, eta digestio-zelulen lisosomen mintzaren egonkortasuna zein lisosomen kopurua eta tamaina 
murrizten ditu $[72,74]$. Bestaldetik, gonada atsedenaldian duten muskuiluetan CAT eta GPx jarduerak baxuak dira, eta estres nutrizionala duten muskuiluetan, aldiz, altuak [75].

\subsection{Urtaroko izateari lotutako aldakortasun naturala}

Tenperaturan, gazitasunean, oxigeno mailan, gametoen garapen-faseetan, jakien eskuragarritasunean eta muskuiluen tamainan gertatzen diren gorabeherak direla medio, urtaroko izateak biomarkatzaile biokimiko eta lisosomikoen gain eragin nabarmena du [38, 76]. Babes antioxidatzailean parte hartzen duten CAT, GST eta GPx moduko entzimek jarduera balio bereziki altuak erakutsi ohi dute udaberrian [75, 76]. Lisosomak, aldiz, beste urtaroetan baino handiagoak dira udan $\left(\mathrm{VV}_{\mathrm{LYS}}\right.$ balio altuak eta $\mathrm{S} / \mathrm{V}_{\mathrm{LYS}}$ balio baxuak), eta mintza ezegonkorragoa dute (LP balio txikiak) [59, 61, 62, 65]. Antza denez, jakien eskuragarritasuna udan handiagoa izateak sasoi horretan ematen den lisosomen jardueraren emendioa dakar, lisosomak handiago eta ugariagoak bilakaturik eta euren mintza ezengonkortuz [36, 62]. Lipofuszinen metaketa udan areagotzen da eskuarki [77, 78]. Ehunmailako biomarkatzaileei dagokienez, badirudi urtaroak ez duela eraginik $\mathrm{V}_{\mathrm{BAS}}$ balioen gain [38]. MLR/MET balioak, berriz, txikiagoak dira udazken hasieran beste sasoietan baino [38]. Urtaroko izateari lotutako aldakortasun naturala aitzakia, Euskal Kostaldeko kutsaduraren monitorizazio-programetan muskuiluak udaberriaren hasieran edo udazkenean biltzea gomendatu izan da, errunaldiaren zein neguko metabolismo baxuaren eragina ahal den neurrian saihestu ahal izateko $[38,59,64]$.

\subsection{Marearteko zonazioari lotutako aldakortasun naturala}

Sesilak izanik marearteko muskuiluek estres termikoari, lehortzeari, anoxiari, olatuen indarrari eta jakien eskuragarritasun ezari aurre egin behar diete emertsio-aldietan derrigorrez. Aitzitik, mareapeko muskuiluak ingurumen egonkorragoan bizi dira. Itsasaldi-marka desberdinetako muskuiluen artean biomarkatzaile biokimiko, lisosomiko eta ehunmailakoetan dauden desberdintasunak aztertuak izan dira [40, 59, 60]. GST jarduera brankietan altuagoa da behe itsasaldi-markako muskuiluetan goikoetan baino; CAT jarduera, aldiz, erdiko itsasaldi-markako muskuiluetan altuagoa da [40, 60]. Haatik, ez dirudi marearteko zonazioak GPx eta AChE jardueren gain eragina duenik [40, 60]. Biomarkatzaile lisosomikoei dagokionez, mintza egonkorragoa da behe itsasaldi-markako muskuiluetan goikoetan baino; lisosomak, berriz, handiagoak dira $[59,60]$. 


\subsection{Laginketa-prodezurari loturiko aldakortasun iturriak}

Ikusi dugunez, marearteko muskuiluen kasuan biomarkatzaile gisa erabilitako zenbait parametroek hartzen dituzten balioak azkar alda daitezke, itsasaldian zehar edo digestiozikloan zehar ordu gutxi, eta baita ere minutu gutxi, ostean. Beraz, muskuiluak zelaiko laginketa-lekutik laborategira garraiatzean eman daitezkeen ingurumen-baldintzen aldaketek biomarkatzaile biokimiko, lisosomiko eta fisiologikoetan eragin bortitza eduki dezakete, biomarkatzaileen balioa eta interpretazioa hein batean kolokan jarriz. Izan ere, laginketan, garraioan eta osteko manipulazioan zehar gerta daitezkeen tenperaturaren aldaketak, hipoxiak, digestio-ziklo eraldatuak eta uretan ala airean garraiotzeak denek batera ekar ditzaketen erantzun biologikoek biomarkatzaile gain eragin esangarria eduki dezakete, biomarkatzaileen interpretazioa zailduz [60, 79]. Hori ekiditeko aldakortasun naturala hobeto ezagutu behar dugu eta ezagumendu horretan oinarrituta jardunbide erabilgarri egokienak kontsentsuatu behar dira. Esate baterako, gaur egun monitorizazio-programetan muskuilu begiraleen laginketari dagokionez honako jardunbide erabilgarri egokien hauek ditugu, nola edo hala, gidari $[59,60]$ :

(a) muskuiluak 0 itsasaldi-markatik ahalik eta gertuen biltzea;

(b) in situ disekzionatzea ahalik eta lasterren (eta beti bilketa osteko hurrengo ordubetean); eta

(c) in situ prozesatzea posiblea ez balitz (ezinbesteko kasuetan), muskuiluak (mareartekoak eta itsasbeheran jasoak) aire pean eta giro tenperaturan garraiatu beharko lirateke, eta ahalik eta denbora laburrenean prozesatu (jaso eta ordubete ostean gehienez).

Oro har, haien baldintza naturalak eta bilketa gunean zeukaten egoera fisiologikoa ahalik eta gutxien aldatzea saiatu behar da, hori da gomendiorik hoberena.

\subsection{Manipulazio esperimentalari loturiko aldakortasun iturriak}

Zelaiko datuak osatzeko eta biomarkatzaileak hobeto ezagutzeko muskuiluak oso erabilgarriak dira laborategiko esperimentuetan. Bertan baldintza esperimentalak kontrolpean mantentzen dira eta horrek lehen aipatutako zenbait nahaste-faktore finkatzen eta euren eragina nolabait ekiditen lagundu dezake. Hala ere, muskuiluak aztergai dituen saiakuntzan beste nahaste-faktore propio atzeman dira, eta horien artean kritikoena elikadura-estrategia da zalantzarik gabe. Izan ere, muskuiluekin egindako laborategiko esperimentu toxikologikoen artean jaki kalitate oso desberdinak eta jaki kantitate oso desberdinak erabili ohi dira, 
muskuiluak baraurik mantentzea barne [69]. Bestalde, elikadura-estrategiaren eragina biomarkatzaileen gain ikerlan gutxi batzuk baino ez dute aztertu. Denok ondorio berberera iritsi dira: elikadura-estrategiak eragina du biomarkatzaileen gain zein kutsatzaile aurrean erantzuteko biomarkatzaileek duten gaitasunaren gain [69, 81-84]. Adibidez, baraurik eta egoki elikatutako muskuiluak fuel baten pean 96 orduz mantendu ostean, biomarkatzaile biokimiko eta lisosomikoen erantzun esangarria elikatutako muskuiluetan soilik antzeman zen [83]. Antza denez, oro har, epe luzeko esperimentu toxikologikoetan bezala epe laburreko esperimentuetan ere muskuiluak elikatzea komenigarria litzateke, orokorki egun egiten ez dena. Halaber, poluitzaile pean egondako muskuiluen egoera nutrizionalak ere eragina eduki dezake biomarkatzaile molekularren gain [84]. Orokorki, laborategiko esperimentuetan, epe luze zein epe laburrekoetan, muskuiluak mantentzeko jaki gisa mikroalga biziez elikatzea jardunbide erabilgarri egokientzat hartu dugu $[69,85,86]$. Hala ere, esparru honetan oso gutxi dakigu, eta jaki mota, osagaiak, hornitze-erregimen eta anoak finkatu arte ikerketa gehiago burutzea beharrezkoa da.

\section{ONDORIOAK}

Ekosistema baten osasun-egoera aztertzeko, antolakuntza biologiko desberdinetako biomarkatzaileak ebaluatzea gomendagarria da. Muskuiluen biomarkatzaileen interpretazio egokia egiteko, nahaste-faktore intrintseko zein estrintsekoak kontuan eduki behar dira. Aurrerapauso nabarmen eman arren [27, 38, 40, 59, 60, 62, 69, 79, 83, 83, 84], biomarkatzaileen aldakortasun naturala hobeto ulertzeko ikerlan gehiago burutu behar dira. Halaber, biomarkatzaile gain nahaste-faktoreek eduki dezaketen eragina hobeto ulertzea ezinbestekoa da zelaiko monitorizazio-programetan zein laborategiko esperimentu toxikologikoetan. Honek ahalbidetuko du muskuiluak behar bezala erabiltzeko beharrezkoak diren jardunbide erabilgarri egokienak garatzea. Jarraibide hauek bermatuko lukete muskuiluen biomarkatzaileetan oinarritutako monitorizazio-programen datuak eta esperimentu toxikologikoen emaitzak euren artean konparagarriak izatea.

\section{BIBLIOGRAFIA}

[1] COMMISSION OF THE EUROPEAN COMMUNITIES. 2005. «Communication from the commission to the council and the European Parliament: Thematic Strategy on the Protection and Conservation of the Marine Environment».

[2] SPIES R.B., RICE S.D., WOLFE D.A., WRIGHT B.A. 1996. «Effects of the Exxon Valdez oil spill on the Alaskan coastal environment». American Fisheries Society Symposium 18, 1-16. 
[3] BOCQUENÉ G., CHANTEREAU S., CLÉRENDEAU C., BEAUSIR E., MÉNARD D., RAFFIN B., MINIER C., BURGEOT T., LESZKOWICZ A.P. eta NARBONNE J.-F. 2004. «Biological effects of the Erika oil spill on the common mussels (Mytilus edulis)». Aquatic Living Resources 17, 309-316.

[4] ADAMS S.M. 2005. «Assessing cause and effect of multiple stressors on marine systems». Marine Pollution Bulletin 51, 649-657.

[5] GARMENDIA L., IZAGIRRE U., CAJARAVILLE M.P., MARIGÓMEZ I. 2011. «Application of a battery of biomarkers in mussel digestive gland to assess longterm effects of the Prestige oil spill in Galicia and the Bay of Biscay: Lysosomal responses». Journal of Environmental Monitoring 13, 901-914.

[6] GARMENDIA L., SOTO M., VICARIO U., KIM Y., CAJARAVILLE M.P., MARIGÓMEZ I. 2011. «Application of a battery of biomarkers in mussel digestive gland to assess long-term effects of the Prestige oil spill in Galicia and Bay of Biscay: Tissue-level biomarkers and histopathology». Journal of Environmental Monitoring 13, 915-932.

[7] ISLAM M.D.S., TANAKA M. 2004. «Impacts of pollution on coastal and marine ecosystems including coastal and marine fisheries and approach for management: a review and synthesis». Marine Pollution Bulletin 48, 624-649.

[8] HYLLAND K., BURGEOT T., MARTÍNEZ-GÓMEZ C., LANG T., ROBINSON C.D., SVAVARSSON J., THAIN J.E., VETHAAK A.D., GUBBINS J. 2017. «How can we quantify impacts of contaminants in marine ecosystems? The ICON project». Marine Environmental Research 124, 2-10.

[9] MELWANI A.R., GREGORIO D., JIN Y., STEPHENSON M., ICHIKAWA G., SIEGEL E., CRANE D., LAUENSTEIN G., DAVIS J.A. 2014. «Mussel watch update: Long-term trends in selected contaminants from coastal California, 19772010». Marine Pollution Bulletin 81, 291-302.

[10]CHIU J.M.Y., PO B.H.K., DEGGER N., TSE A., LIU W., ZHENG G., ZHAO D.-M., XU D., RICHARSON B., WU R.S.S. 2018. «Contamination and risk implications of endocrine disrupting chemicals along the coastline of China: A systematic study using mussels and semipermeable membrane devices». Science of Total Environment 624, 1298-1307.

[11]GOLDBERG E.D., BOWEN V.T., FARRINGTON J.W., HARVEY G., MARTIN J.H., PARKER P.L., RISEBROUGH R.W., ROBERTSON W., SCHNEIDER W., GAMBLE E. 1978. «The Mussel Watch». Environmental Conservation 5, 101-125.

[12] OSPAR. 1998. «JAMP guidelines for general biological effects monitoring». Technical Annexes 1-3, Oslo and Paris Commission, London.

[13]JHA A.N., CHEUNG V.V., FOULKES M.E., HILL S.J., DE- PLEDGE M.H. 2000. «Detection of genotoxins in the marine environment: adoption and evaluation of 
an integrated approach using the embryo-larval stages of the marine mussel Mytilus edulis». Mutation Research 464, 213-228.

[14]LAANE R.W.P.M., SLIJKERMAN D., VETHAAK A.D., SCHOBBEN J.H.M. 2012. «Assessment of the environmental status of the coastal and marine aquatic environment in Europe: A plea for adaptive management». Estuarine, Coastal and Shelf Science 96, 31-38.

[15]MARTÍNEZ-GÓMEZ C., ROBINSON C.D., BURGEOT T., GUBBINS M., HALLDORSSON H.P., ALBENTOSA M., BIGNELL J.P., HYLLAND K., VETHAAK A.D. 2017. «Biomarkers of general stress in mussels as common indicators for marine biomonitoring programmes in Europe: The ICON experience». Marine Environmental Research 124, 70-80.

[16]VIARENGO A., LAFAURIE M., GABRIELIDES G.P., FABBRI R., MARRO A., ROMÉO M. 2000. «Critical evaluation of an intercalibration exercise undertaken in the framework of the MED POL biomonitoring program». Marine Environmental Research 49, 1-18.

[17]NYGÅRD H., BERGSTRÖM L., MURRAY C., MARTIN G., FLEMINGLEHTINEN V., ANDERSEN J., TORN K., SUIKKANEN S., ZWEIFEL U.L., AVELLAN L., HOIKKALA L., KAITARANTA J., ESTLANDER S., KORPINEN S. 2017. «The integrated assessment of biodiversity -Supplementary Report to the First Version of the "State of the Baltic Sea" HELCOM Report 2017».

[18] VIARENGO A., LOWE D., BOLOGNESI C., FABBRI E., KOEHLER A. 2007. «The use of biomarkers in biomonitoring: A 2-tier approach assessing the level of pollutant-induced stress syndrome in sentinel organisms». Comparative Biochemistry and Physiology 146C, 281-300.

[19]BEYER J., GREEN N.W., BROOKS S., ALLAN I.J., RUUS A., GOMES T., BRATE I.L.N., SCHØYEN M. 2017. «Blue mussels (Mytilus edulis spp.) as sentinel organisms in coastal pollution monitoring: A review». Marine Environmental Research 130, 338-365.

[20]ICES. 2012. «Integrated marine environmental monitoring of chemicals and their effects». By Davies IM and Vethaak AD. ICES Cooperative Research Report No. 315.

[21]UNEP/RAMOGE. 1999. «Manual on the biomarkers recommended for the MED POL biomonitoring programme». UNEP.

[22]MOORE MN. 2004. «Diet restriction induced autophagy: A lysosomal protective system against oxidative- and pollutant-stress and cell injury». Marine Environmental Research 58, 603-607.

[23]MCDONALD J.H., SEED R., KOEHN R.K. 1991. «Allozymes and morphometric characters of three species of Mytilus in the Northern and Southern Hemispheres». Marine Biology 111, 323-333. 
[24]HILBISH T.J., MULLINAX A., DOLVEN S.I., MEYER A., KOEHN R.K., RAWSON P.D. 2000. «Origin of the antitropical distribution pattern in marine mussels (Mytilus spp.): routes and timing of transequatorial migration». Marine Biology 136, 69-77.

[25] GARDNER J.P.A. 1996. «The Mytilus edulis species complex in southwest England: the extent of hybridization and introgression and their effects upon interlocus associations and morphometric variation». Marine Biology 125, 385-399.

[26] GARDNER J.P.A., THOMPSON R.J. 2001. «The effects of coastal and estuarine conditions on the physiology and survivorship of the mussels Mytilus edulis, M. trossulus and their hybrids». Journal of Experimental Marine Biology and Ecology 265, 119-140.

[27]BROOKS S.J., FARMEN E., HEIER L.S., BLANCO-RAYÓN E., IZAGIRRE U. 2015. «Differences in copper bioaccumulation and biological responses in three Mytilus species». Aquatic Toxicology 160, 1-12.

[28] GOSLING E. 2004. Bivalve molluscs: biology, ecology and culture. Fishing News Book, Great Britain.

[29] SEED R., SUCHANEK T.H. 1992. Population and community ecology of Mytilus. In: The Mussel Mytilus: Ecology, Physiology, Genetics and Culture. Elsevier Science Publishers B.V., London.

[30] SEED R. 1971. «A physiological and biochemical approach to the taxonomy of Mytilus edulis L. and M. galloprovincialis Lmk. from S.W. England». Cahiers de Biologie Marine 12, 291-322.

[31]CAJARAVILLE M.P., GARMENDIA L., ORBEA A., WERDING R., GÓMEZ-MENDIKUTE A., IZAGIRRE U., SOTO M., MARIGÓMEZ I. 2006. «Signs of recovery of mussels health two years after the Prestige oil spill». Marine Environmental Research 62 Suppl, S337-341.

[32]ICES. 2011. «ICES / OSPAR SGIMC REPORT 2011 Monitoring of Contaminants and Biological Report of the Study Group on Integrated Effects (SGIMC) International Council for the Exploration of the Sea».

[33]ORTIZ-ZARRAGOITIA M., GARMENDIA L., BARBERO M.C., SERRANO T., MARIGÓMEZ I., CAJARAVILLE M.P. 2011. «Effects of the fuel oil spilled by the Prestige tanker on reproduction parameters of wild mussel populations». Journal of Environmental Monitoring 13, 84-94.

[34]HINES A, YEUNG WH, CRAFT J, BROWN M, KENNEDY J, BIGNELL J, STENTIFORD GD, MR VIANT. 2007. «Comparison of histological, genetic, metabolomics, and lipid-based methods for sex determination in marine mussels». Analytical Biochemistry 369, 175-186. 
[35]KIM Y., POWELL E.N. 2006. «Relationships among parasites and pathologies in sentinel bivalves: NOAA Status and Trends "Mussel Watch" Program». Bulletin of Marine Science 79, 83-111.

[36] MÚGICA M., SOKOLOVA I.M., IZAGIRRE U., MARIGÓMEZ I. 2015. «Season-dependent effects of elevated temperature on stress biomarkers, energy metabolism and gamete development in mussels». Marine Environmental Research 103, $1-10$.

[37] VILLALBA A. 1995. «Gametogenic cycle of cultured mussel, Mytilus galloprovincialis, in the bays of Galicia (N.W. Spain)». Aquaculture 130, 269-277.

[38] GARMENDIA L., SOTO M., CAJARAVILLE M.P., MARIGÓMEZ I. 2010. «Seasonality in cell and tissue-level biomarkers in Mytilus galloprovincialis: relevance for long-term pollution monitoring». Aquatic Biology 9, 203-219.

[39] VIDAL-LIÑÁN L., BELLAS J. 2013. «Practical procedures for selected biomarkers in mussels, Mytilus galloprovincialis - Implications for marine pollution monitoring». Science of Total Environment 461-462, 56-64.

[40] MORTON B. 1983. Feeding and digestion in bivalvia. In: The Mollusca $\mathrm{n}^{\circ}$ 5, Academic Press, London.

[41]Fernandez-Reiriz M.J., Labarta U., Navarro J.M., Velasco A. 2001. «Enzymatic digestive activity in Mytilus chilensis (Hupé 1854) in response to food regimes and past feeding history». Journal of Comparative Physiology B 171, 449456.

[42]RASMUSSEN L.P., HAGE E., KARLOG O. 1983. «Histopathological studies of the acute and chronic toxic effects of $2 \mathrm{~N}$-nitroso compounds on the blue mussel (Mytilus edulis)». Nordisk Veterinaermedicin 35, 306-313.

[43]MARIGÓMEZ I., CAJARAVILLE M.P., ANGULO E. 1990. «Histopathology of the digestive gland-gonad complex of the marine prosobranch Littorina littorea exposed to cadmium». Diseases of Aquatic Organisms 9, 229-238.

[44]ZALDIBAR B., CANCIO I., SOTO M., MARIGÓMEZ I. 2008. «Changes in cell-type composition in digestive gland of slugs and its influence in biomarkers following transplantation between a relatively unpolluted and a chronically metalpolluted site». Environmental Pollution 156, 367-379.

[45] OWEN G. 1972. «Lysosomes, peroxisomes and bivalves». Science Progress 60, 299-318.

[46]ALLISON A.C., YOUNG M.R. 1969. Vital staining and fluorescence microscopy of lysosomes. In: Dingle JT, Fell HB (Eds.) Lysosomes in biology and pathology. Elsevier, London. 
[47]MOORE M.N., SOVERCHIA C., THOMAS M. 1996. «Enhanced lysosomal autophagy of intracellular proteins by xenobiotics in living molluscan blood cells». Acta Histochemica et Cytochemica 29, 947-948.

[48] MOORE M.N. 1985. «Cellular responses to pollutants». Marine Pollution Bulletin 16, 134-139.

[49]CAJARAVILLE M.P., ROBLEDO Y., ETXEBERRIA M., MARIGÓMEZ I. 1995. Cellular biomarkers as useful tools in the biological monitoring of environmental pollution: molluscan digestive lysosomes. In: Cajaraville MP (Eds). Cell biology in environmental toxicology. University of the Basque Country Press Service, Bilbo.

[50] OWEN G. 1996. Feeding. In: KM Wilburn and CM Yonge (Eds.) Physiology of Mollusca, vol 2. Academic Press, London.

[51] WEINSTEIN J.E. 1995. «Fine structure of the digestive tubule of the Eastern oyster, Crassostrea virginica (Gmelin 1791)». Journal of Shellfish Research 14, 97103.

[52]LEKUBE X., CAJARAVILlE M.P., MARIGÓMEZ I. 2000. «Use of polyclonal antibodies for the detection of changes induced by cadmium in lysosomes of aquatic organisms». The Science of the Total Environment 247, 201-212.

[53]IZAGIRRE U., RUIZ P., MARIGÓMEZ I. 2009. «Time-course study of the early lysosomal responses to pollutants in mussel digestive cells using acid phosphatase as lysosomal marker enzyme». Comparative Biochemistry and Physiology 149C, 587-597.

[54]PAONE J.F., WAALKES T.P., BAKER R.R., SHAPER J.H. 1980. «Serum UDP-galactosyl transferase as a potential biomarker for breast carcinoma». Journal Surgical Oncology 15, 59-66.

[55] MCCARTHY J.F., SHUGART L.R. 1990. Biomarkers of environmental contamination. Lewis Publishers, Boca Raton.

[56] PEAKALL D.B. 1994. «The role of biomarkers in environmental assessment (1). Introduction». Ecotoxicology 3, 157-160.

[57] Storey K. B. 1996. «Oxidative stress: animal adaptations in nature». Brazilian Journal of Medical and Biological Research 29, 1715-1733.

[58] Halliwell B. 1992. «Reactive oxygen species and the central nervous system». Journal of Neurochemistry 59, 1609-1623.

[59]IZAGIRRE U., RAMOS R.R., MARIGÓMEZ I. 2008. «Natural variability in size and membrane stability of lysosomes in mussel digestive cells: seasonal and tidal zonation». Marine Ecology Progress Series 372, 105-117.

[60]BLANCO-RAYÓN E., GUILHERMINO L., MARIGÓMEZ I., IZAGIRRE U. 2019. «Collection and transport of sentinel mussels in biomarker-based coastal 
pollution monitoring: Current flaws and reliable practices». Ecological Indicators 103, 722-734.

[61]MARIGÓMEZ I., ORBEA A., OLABARRIETA I., ETXEBARRIA M., CAJARAVILLE M.P. 1996. «Structural changes in the digestive lysosomal system of sentinel mussels as biomarkers of environmental stress in Mussel Watch Programmes». Comparative Biochemistry and Physiology 113C, 291-297.

[62]BLANCO-RAYÓN E. 2018. Contribution to the development of Best Available Practices (BAPS) for a multi-biomarker approach in sentinel mussels based on a better understanding of the influence of confounding factors on biomarker values and responsiveness. $\mathrm{PhD}$ Thesis, University of the Basque Country, Bilbo.

[63]HILBISH T.J., CARSON E.W., PLANTE J.R., WEAVER L.A., GILG M.R. 2002. «Distribution of Mytilus edulis, M. galloprovincialis, and their hybrids in opencoast populations of mussels in south western England». Marine Biology 140, 137142.

[64]IZAGIRRE U., GARMENDIA L., SOTO M., ETXEBARRIA N., MARIGÓMEZ I. 2014. «Health status assessment through an integrative biomarker approach in mussels of different ages with a different history of exposure to the Prestige oil spill». Science of the Total Environment 493, 65-78.

[65]LIU X., SUN H., WANG Y., MA M., ZHANG Y. 2014. «Gender-specific metabolic responses in hepatopancreas of mussel Mytilus galloprovincialis challenged by Vibrio harveyi». Fish \& Shellfish Immunology 40, 407-413.

[66]JI C., LI F., WANG Q., ZHAO J., SUN Z., WU H. 2016. «An integrated proteomic and metabolomics study on the gender-specific responses of mussels Mytilus galloprovincialis to tetrabromobisphenol A (TBBPA)». Chemosphere 144, 527-539.

[67]ZILBERBERG C., SERENO D., LIMA G., CUSTÓDIO M.R., LÔBOHAJDU G. 2011. «Effect of mussel's gender and size on a stress response biomarker». Water, Air \& Soil Pollution 217, 317-320.

[68] GONZÁLEZ-FERNÁNDEZ C, ALBENTOSA M, SOKOLOVA I. 2017. «Interactive effects of nutrition, reproductive state and pollution on molecular stress responses of mussels, Mytilus galloprovincialis Lamarck, 1819». Marine Environmental Research 131, 103-115.

[69]BLANCO-RAYÓN E., IVANINA A.V., SOKOLOVA I.M., MARIGÓMEZ I., IZAGIRRE U. 2019. «Food-type may jeopardize biomarker interpretation in mussels used in aquatic toxicological experimentation». Plos One, 14(8): e0220661.

[70]DOMOUHTSIDOU G.P., DIMITRIADIS V.K. 2000. «Ultrastructural localization of heavy metals $(\mathrm{Hg}, \mathrm{Ag}, \mathrm{Pb}$, and $\mathrm{Cu})$ in gills and digestive gland of mussels, Mytilus galloprovincialis (L.)». Archives of Environmental Contamination and Toxicology 38, 472-478. 
[71]CANCIO I., IBABE A., CAJARAVILLE M.P. 1999. «Seasonal variation of peroxisomal enzyme activities and peroxisomal structure in mussels Mytilus galloprovincialis and its relationship with the lipid content». Comparative Biochemistry and Physiology 123C, 135-144.

[72]KHESSIBA A., ROMÉO M., AISSA P. 2005. «Effects of some environmental parameters on catalase activity measured in the mussel (Mytilus galloprovincialis) exposed to lindane». Environental Pollution 133, 275-81.

[73] VERLECAR X.N., JENA K.B., CHAINY G.B.N. 2007. «Biochemical markers of oxidative stress in Perna viridis exposed to mercury and temperature». Chemico-Biological Interactions 167, 219-26.

[74]BAYNE B.L., MOORE M.N., KOEHN R.K. 1981. «Lysosomes and the response by Mytilus edulis L. to an increase in salinity». Marine Biology Letters 2, 193-204.

[75]GONZÁLEZ-FERNÁNDEZ C., ALBENTOSA M., CAMPILlO J.A., VIÑAS L., FRANCO A., BELLAS J. 2016. «Effect of mussel reproductive status on biomarker responses to PAHs: Implications for large-scale monitoring programs». Aquatic Toxicology 177, 380-394.

[76]NAHRGANG J., BROOKS S.J., EVENSET A., CAMUS L., JONSSON M., SMITH T.J., LUKINA J., FRANTZEN M., GIARRATANO E., RENAUD P.E. 2013. «Seasonal variation in biomarkers in blue mussel (Mytilus edulis), Icelandic scallop (Chlamys islandica) and Atlantic cod (Gadus morhua)-Implications for environmental monitoring in the Barents Sea». Aquatic Toxicology 127, 21-35.

[77]BOCCHETTI R., REGOLI F. 2006. «Seasonal variability of oxidative biomarkers, lysosomal parameters, metallothioneins and peroxisomal enzymes in the Mediterranean mussel Mytilus galloprovincialis from Adriatic Sea». Chemosphere 65, 913-921.

[78]BRENNER M., BROEG K., FRICKENHAUS S., BUCK B.H., KOEHLER A. 2014. «Multi-biomarker approach using the blue mussel (Mytilus edulis L.) to assess the quality of marine environments: Season and habitat-related impacts». Marine Environmental Research 95, 13-27.

[79]CHANDURVELAN R., MARSDEN I.D., GAW S., GLOVER C.N. 2012. «Impairment of green-lipped mussel (Perna canaliculus) physiology by waterborne cadmium: Relationship to tissue bioaccumulation and effect of exposure duration». Aquatic Toxicology 124-125, 114-124.

[80]LOBEL P.B., BAJDIK C.D., BELKHODE S.P., JACKSON S.E., LONGERICH H.P. 1991. «Improved Protocol for Collecting Mussel Watch Specimens Taking into Account Sex, Size, Condition, Shell Shape, and Chronological Age». Archives of Environmental Contamination and Toxicology 21, 409-414. 
[81]MOORE M.N., VIARENGO A., DONKIN P., HAWKINS A.J.S. 2007. «Autophagic and lysosomal reactions to stress in the hepatopancreas of blue mussels». Aquatic Toxicology 84, 80-91.

[82]IBARROLA I., ETXEBERRIA M., IGLESIAS J.I.P., URRUTIA M.B., ANGULO E. 2000. "Acute and acclimated digestive responses of the cockle Cerastoderma edule (L.) to changes in the food quality and quantity II. Enzymatic, cellular and tissular responses of the digestive gland». Journal of Experimental Marine Biology and Ecology 252, 199-219.

[83]BLANCO-RAYÓN E., GUILHERMINO L., IRAZOLA M., IVANINA A. V., SOKOLOVA I. M., IZAGIRRE U., MARIGÓMEZ I. 2019. «The influence of short-term experimental fasting on biomarker responsiveness in oil WAF exposed mussels». Aquatic Toxicology 206, 164-175.

[84]GONZÁLEZ-FERNÁNDEZ C., ALBENTOSA M., CAMPILlO J.A., VIÑAS L., ROMERO D., FRANCO A., BELLAS J. 2015. «Effect of nutritive status on Mytilus galloprovincialis pollution biomarkers: Implications for large-scale monitoring programs». Aquatic Toxicology 167, 90-105.

[85] ALBENTOSA M, PÉREZ-CAMACHO A, LABARTA U, FERNÁNDEZREIRIZ MJ. 1997. «Evaluation of freeze-dried microalgal diets for the seed culture of Ruditapes decussatus using physiological and biochemical parameters». Aquaculture 154, 305-321.

[86]FERNÁNDEZ-REIRIZ M.J., IRISARRI J., LABARTA U. 2015. «Feeding behaviour and differential absorption of nutrients in mussel Mytilus galloprovincialis: Responses to three microalgae diets». Aquaculture 446, 42-47. 